\title{
Nota sobre registro fotográfico e observações preliminares de puerulus a juvenil de Panulirus argus após o assentamento em macroalgas Amansia sp. no Brasil
}

\section{Note on photographic register and preliminary observations from puerulus to juvenile of Panulirus argus after settlement in Amansia sp. macroalgae in Brazil}

\author{
Marco Antonio Igarashi ${ }^{1}$
}

\begin{abstract}
Resumo
Puerulus de Panulirus argus assentam geralmente em locais rasos, tipicamente e solitariamente em ramos de algas vermelhas como a Amansia sp. Este tipo de habitat pode ser encontrado em muitas áreas da Costa do Estado do Ceará, onde a macroalga Amansia sp. associado com outros gêneros de macroalgas e fendas nas rochas funcionam como habitat para juvenis. O objetivo desse trabalho foi contribuir no conhecimento do comportamento e habitat de puerulus e juvenil de $P$. argus no Brasil.

Palavras-chave: Habitat, puerulus, juvenis, Panulirus argus, nordeste do Brasil
\end{abstract}

\begin{abstract}
Puerulus of Panulirus argus settlement is generally in the shallows and typically reside solitary in branched red algae Amansia sp. This type of habitat may be found in many areas of the Ceara State Coast, where macroalgae Amansia sp. with associated other genera of macroalgae and crevice shelters function as habitat for young juvenile spiny lobster. The objective of this work was to help to explain the settlement of puerulus and juvenile of $P$. argus in the coast of Ceará, Brazil and their behaviour.
\end{abstract}

Key words: Habitat, puerulus, juveniles, Panulirus argus, northeast of Brazil

\footnotetext{
${ }^{1} \mathrm{PhD}$ em Engenharia de Pesca pela Universidade Kitasato, Japão. Professor Associado do Departamento de Engenharia de Pesca da Universidade Federal do Ceará a disposição do Ministério da Pesca e Aquicultura. E-mail: igarashi@ufc.br; marco.igarashi@, mpa.gov.br
} 


\section{Introdução}

Três espécies de lagostas espinhosas são comercialmente capturadas na costa do Brasil (Panulirus argus, P. laevicauda e P. echinatus), representando uma entrada de divisas da ordem de 50 a 60 milhões de dólares (GÓES, 2006). Entre as três espécies no Nordeste do Brasil, duas espécies desfrutam de grande importância econômica, a saber: a vermelha (P. argus) e a cabo-verde ( $P$. laevicauda) cujas capturas se fazem principalmente com o covo, também denominado manzuá, arte de pesca preconizada pelo IBAMA (IGARASHI, 2007). Ressalta-se, ainda, que a região nordeste é a principal produtora do referido crustáceo, cuja produção majoritária cabe geralmente ao Estado do Ceará, as quais em 2007 orçaram em 2.186 toneladas.

A lagosta $P$. argus sustenta uma das mais importantes capturas mundiais compreendendo aproximadamente $46 \%$ do total da captura de lagostas espinhosas (GOLDSTEIN; MATSUDA; BUTLER, 2006). A lagosta $P$. argus ocorre no mar do Caribe Golfo do México e costa nordeste do Brasil (WILLIAMS, 1988).

A $P$. argus atinge a maturidade sexual com o comprimento da carapaça de aproximadamente 70 - 80 mm (WITHAM; INGLE; JOYCE, 1968; OLSEN; HERRNKIND; COOPER, 1975). No acasalamento ocorre a liberação do espermatóforo o qual adere no esterno da fêmea. A fertilização ocorre, quando as fêmeas arranham o espermatóforo para liberar os espermatozóides que fecundam os óvulos.

As fêmeas com o tamanho do cefalotórax de 71$75 \mathrm{~mm}$ carregam aproximadamente 230.000 ovos; enquanto fêmeas com mais de $100 \mathrm{~mm}$ carregam mais de 700.000 ovos (MOTA-ALVES; BEZERRA 1968). Os ovos são de coloração alaranjado brilhante e aproximadamente $1 \mathrm{~mm}$ em diâmetro (LEWIS, 1951). Porém há relatos de tamanhos menores em diâmetro. Elas eclodirão em aproximadamente 3 semanas. Vários dias antes de ocorrer a eclosão, os ovos ficam marrom escuro.

Após o período de incubação do ovo, eclode a larva denominada de filosoma que se alimenta de animais planctônicos (MOE JUNIOR, 1991). As larvas filosomas são achatadas dorsoventralmente, animais praticamente transparentes, com grandes modificações para a existência planctônica (LEWIS, 1951), sendo transportados pelas correntes oceânicas por 6-12 meses antes da metamorfose para o estágio de puerulus (LYONS et al., 1981). O tamanho inicial da larva pode ser de aproximadamente 2 mm de comprimento total após a eclosão. As larvas filosomas metamorfosearam para puerulus após 18 - 21 mudas (média $=19,7)$ (GOLDSTEIN; MATSUDA; BUTLER, 2006). A fase de puerulus é um estágio transicional do filosoma para o juvenil bentônico (KITTAKA, 2000). O comprimento do corpo no estágio final de filosoma e estágio de $P$. argus variou de 25,60 - 28,20 $\mathrm{mm}$ (média $=$ $27,00 \mathrm{~mm}$ ) e $16,40-17,50 \mathrm{~mm}$ comprimento do corpo $\mathrm{BL}$ (média $=17,00 \mathrm{~mm}$ ), respectivamente (GOLDSTEIN; MATSUDA; BUTLER, 2006).

Assim sendo, considerando-se a importância econômica da lagosta $P$. argus para o Brasil e o fato de que são escassas as informações disponíveis sobre o assentamento de puerulus de $P$. argus no Brasil, nessa breve comunicação, nós realizamos provavelmente pela primeira vez no Brasil um registro fotográfico desde o assentamento do puerulus até o estágio de juvenil em macroalgas Amansia sp. visando contribuir no conhecimento do comportamento e caracterizar o habitat natural dos pueruli de $P$. argus.

\section{Material e Métodos}

As algas da espécie Amansia sp. foram coletadas na praia de Fortaleza-CE nas marés baixas de sizígia, momento em que os recifes areníticos de praia ou "beach rocks" afloram, tomando devido cuidado de anotar a localização exata e caracterização do 
meio em que vivem. Este local é recoberto por uma grande quantidade de macroalgas Amansia sp. formando uma estrutura complexa, fornecendo aos juvenis abrigo e alimento como inúmeros moluscos, crustáceos e peixes. Estas algas foram coletadas por inteiro, segurando firmemente pela base ainda na água arrancadas e introduzidas dentro do puçá. As algas foram introduzidas em baldes e vasculhadas detalhadamente, pois os pueruli são praticamente transparentes na fase inicial de desenvolvimento. O material registrado neste trabalho constou de 3 indivíduos, medindo entre 17,00 e $21,5 \mathrm{~mm}$ de comprimento total e pesando entre $0,13-0,22$ gramas.

Os pueruli foram mantidos em aquários de $40 \mathrm{~cm}$ x $20 \mathrm{~cm}$ x $25 \mathrm{~cm}$ individualmente. A água foi diariamente renovada. A salinidade, $\mathrm{pH}$ e temperatura foram medidos periodicamente.

A alga Amansia sp. foi identificada de acordo com Joly (1967), relacionando-se as características externas observadas e o nome vulgar com o científico. Os sete dias de puerulus e a fase de juvenil foram registrados com uma câmera digital Nikon Colpix 4200. Após a finalização dos estudos, os indivíduos foram reintroduzidos ao habitat.

O experimento foi conduzido no laboratório do Centro de Tecnologia em Aquicultura - CTA, na Universidade Federal do Ceará - UFC, Fortaleza Brasil.

\section{Resultados e Discussão}

$\mathrm{Na}$ natureza o puerulus aparentemente navega para o berçário de juvenis através do complexo sistema receptor formado pelo sistema de antenas e setas penado, e uma vez no berçário, o puerulus assenta em habitats selecionados (MIKAMI; KUBALA, 2004) e tendem permanecer poucos centímetro da superfície da água (LYONS, 1980).

Uma vez no berçário, os pueruli preferem assentar em um habitat de arquitetura complexa, podendo se assentar nos berçários de algas (WITHAM; INGLE;
SIMS JUNIOR, 1964). A preferência por estes habitats é mediado pela estrutura complexa e não pela disponibilidade de alimentos.

No Estado do Ceará os pueruli de P. argus foram encontrados em algas Amansia sp. e em menor quantidade nas algas Cryptonema sp. Os pueruli de $P$. argus, se juntam em grande número em habitats apropriados (raízes de mangue) e podem ser capturados com coletores artificiais que se assemelham as algas aglomeradas que procuram por refúgio (MARX; HERRNKIND, 1985). Por outro lado de acordo com Herrkind e Butler (1986) os pueruli de $P$. argus preferem assentar em algas vermelhas Laurencia. Além disso no sul da Flórida, juvenis de $P$. argus com menos de $15 \mathrm{~mm}$ de tamanho de carapaça residem principalmente em algas vermelhas que fornecem alimento e abrigo, sendo a alga do gênero Laurencia (LIPCIUS; COBB, 1994).

O puerulus de $P$. argus muda para o primeiro estágio bentônico em 7 - 10 dias no verão (em temperatura $>29{ }^{\circ} \mathrm{C}$ ) e $14-28$ dias no inverno (em temperatura $<20^{\circ} \mathrm{C}$; FIELD; BUTLER, 1994; BUTTLER; HERRNKIND, 2000). Os pueruli persistem por várias semanas, não se alimentam e são oceânicos (LYONS, 1980; HERRKIND; BUTLER, 1986; KITTAKA, 2000). Segundo Goldstein, Matsuda e Butler (2006) em cativeiro as lagostas $P$. argus foram cultivadas desde o ovo até puerulus em 140 a 198 dias (média $=173,8$ dias). De acordo com os mesmos autores nesse sistema de cultivo as lagostas $P$. argus cultivadas desde o ovo às formas bentônicas foram mantidas em temperaturas entre 25 e $27^{\circ} \mathrm{C}$.

Vários dias após o estágio de puerulus, ocorrem a primeira muda para o estágio de juvenil, e começam a se pigmentar, com a coloração vermelho marrom. Os juvenis bentônicos crypticamente colorido variam com o abrigo. Os juvenis mais jovens tendem ser solitário e comportam-se agressivamente.

No presente experimento não se observou pueruli de lagostas $P$. argus nas pequenas fendas. 
Por outro lado os juvenis maiores com mais de 10 gramas foram observados com frequência nas fendas encontradas nas poças formadas nas marés baixa.

A quantidade de algas vermelhas na costa do Estado do Ceará pode variar conforme a época do ano. Porém não se observou preliminarmente a diminuição de lagostas juvenis recentes devido a diminuição na quantidade de algas. Além disso, em observações realizadas, a quantidade de puerulus na costa do Ceará pode variar durante os meses do ano. Não se tem, ainda, um estudo determinando a abundância de puerulus como em alguns países nos quais se torna possível economicamente a captura e a engorda até o tamanho legal. Portanto em alguns países utilizam coletores artificiais para capturar o puerulus com o objetivo de engorda em cativeiro.

Um dia após a captura o puerulus de $P$. argus da Figura 1, adquiriu uma pigmentação parda, em forma de listras longitudinais parda e branca na região dorsal. A pigmentação parda ocorreu nos pedúnculos, antenas e nos pereiópodos. Por observação posterior dos indivíduos, nota-se que a pigmentação, visível através do exoesqueleto transparente, indica a formação de uma nova carapaça que representa o início do primeiro estágio juvenil. Phillips e Sastry (1980) citado por Conceição (1987) reporta que, para $P$. argus, o estágio puerulus em águas costeiras geralmente passa por duas mudanças de carapaça dentro de um período de 5-10 dias. Por outro lado no presente experimento o puerulus de $P$. argus nesse mesmo período passou por apenas 1 muda de exoesqueleto quando passou para o estágio de juvenil.

Após o assentamento, o puerulus se locomove através de seus 5 pares de pereiópodos, caminhando em qualquer direção. Locomove-se para trás, quando em fuga, dobrando rapidamente abdômen com os urópodos e o telso aberta em leque; ao mesmo tempo as patas e antenas ficam direcionadas para a frente, formando uma massa compacta e alongada, para agilizar o movimento.

\section{Conclusão}

Os pueruli se assentam no habitat bentônico, como as macroalgas Amansia sp. existentes em áreas costeiras e iniciam uma fase em que são encontradas em grupos de algas. O puerulus de $P$. argus é praticamente transparente ao assentar em macroalgas Amansia sp. Durante o assentamento a sua coloração muda inicialmente de um pardo para um marrom avermelhado. Durante o período de assentamento os pueruli não se alimentaram. As lagostas juvenis recentes preferem assentar em algas vermelhas e com o desenvolvimento da lagosta os juvenis passam a se esconder nas fendas encontradas entre as rochas na região costeira do litoral. 


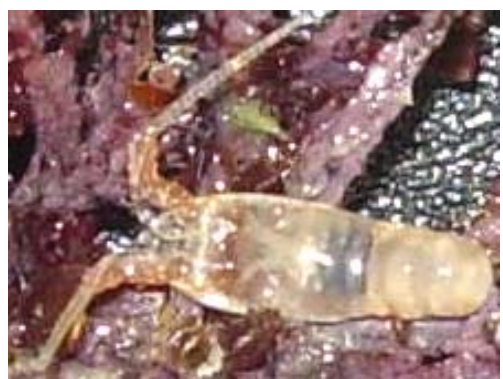

(a) Puerulus de Panulirus argus no dia da captura

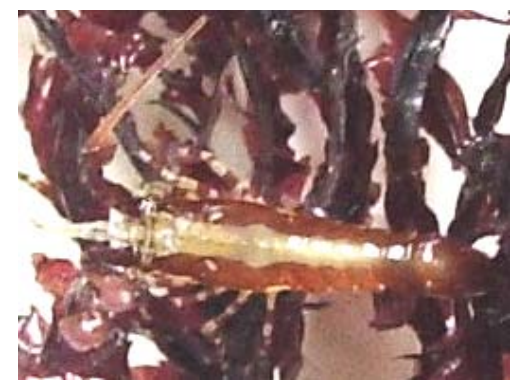

(d) Puerulus de Panulirus argus com 4 dias após a captura

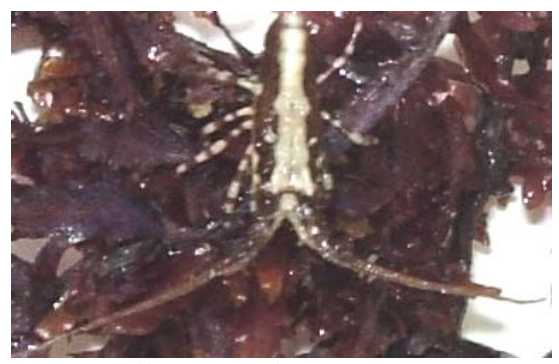

(g) Juvenil recente de Panulirus argus no primeiro dias após a muda do exoesqueleto e 7 dias após a captura

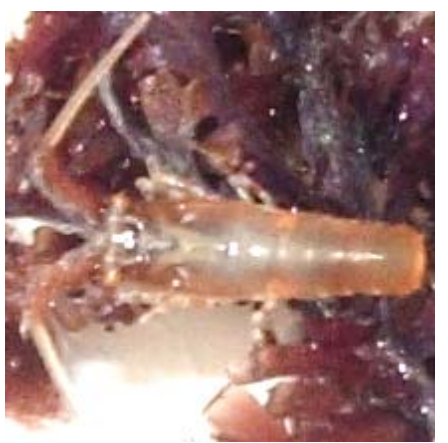

(b) Puerulus de Panulirus argus com 2 dias após a captura

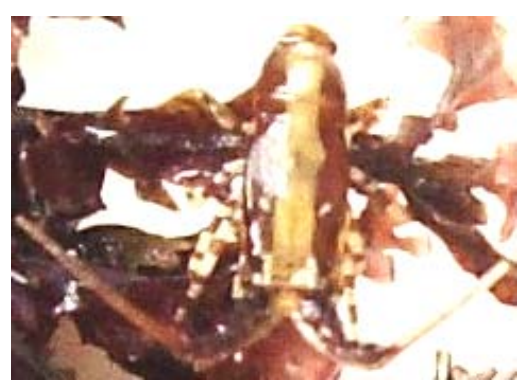

(e) Puerulus de Panulirus argus com 5 dias após a captura

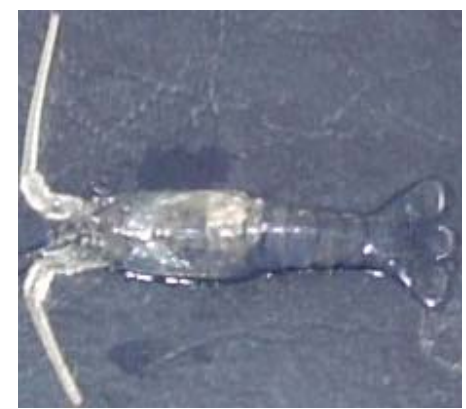

(h) Exosqueleto do puerulus de Panulirus argus

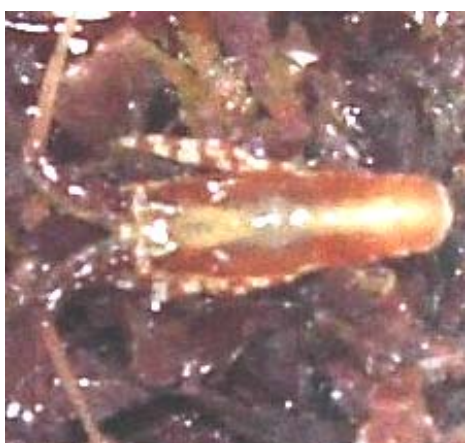

(c) Puerulus de Panulirus argus com 3 dias após a captura

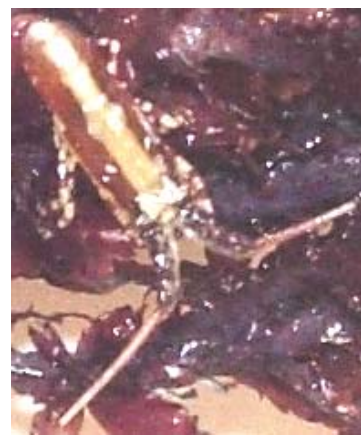

(f) Puerulus de Panulirus argus com 6 dias após a captura

Figura 1. Período de assentamento de puerulus de Panulirus agus (a, b, c, d, e, f) em algas Amansia sp. até a muda para o estágio de juvenil (g). 


\section{Agradecimentos}

Agradeço ao Professor Jiro Kittaka da Universidade de Ciência de Tokyo pelas informações fornecidas sobre o assentamento de lagostas.

\section{Referências}

BUTLER, M. J. I.V.; HERRKIND, W. F. Puerulus and Juvenile Ecology. In: PHILLIPS, B. F.; KITTAKA, J. (Ed.). Spiny lobster: fisheries and culture. Cambridge: Fishing News Books, 2000, p. 276-301.

CONCEIÇÃO, R. N. L. Ocorrência de puerulus de Panulirus laevicauda (Latreille) nas capturas de arrastão de praia no município de Fortaleza (Ceará, Brasil). Arquivo de Ciências do Mar, Fortaleza, v. 26, n. 1, p. 83-85, 1987.

FIELD, J. M.; BUTLER, M. J. I. V. The influence of temperature, salinity, and postlarval transport on the distribution of juvenile spiny lobsters, Panulirus argus (Latreille, 1804) in Florida Bay. Crustaceana, Leiden, v. 67, n. 1, p. 26-45, 1994.

GÓES, C. A. Análise da dispersão de larvas de lagostas no atlântico tropical a partir de correntes geostróficas superficiais derivadas por satélites. 2006. Dissertação (Mestrado em Sensoriamento Remoto INPE) - Instituto Nacional de Pesquisas Espaciais, São José dos Campos. Disponível em: $<$ h ttp:// mtc- m17. sid.inpe. br/ col/ sid.inpe.br/ MTC-m $13 @ 80 / 80 / 2006 / 07.10 .14 .12 /$ doc/ publicacao. pdf $>$. Acesso em: 07 jul. 2007.

GOLDSTEIN, J.; MATSUDA, H.; BUTLER, M. J. I. V. Success! caribbean spiny lobster, Panulirus argus is cultured from egg to juvenile for the first time. The Lobster Newsletter, Norfolk, v. 19, n. 1, p. 3-5, 2006.

HERRNKIND, W. F.; BUTLER, M. J. I. V. Factors regulating postlarval settlement and juvenile microhabitat use by spiny lobsters Panulirus argus. Marine Ecology Progress Series, Richmond, v. 34, n. 1, p. 23-30, 1986.

IGARASHI, M. A. Sinopse da situação atual, perspectivas e condições de cultivo para lagostas Palinuridae. Ciência Animal Brasileira, Goiânia, v. 8, n. 2, p. 155-166, 2007.

JOLY, A. B. Gêneros de algas marinhas da Costa Atlântica Latino Americana. São Paulo: Editora da Universidade de São Paulo, 1967.

KITTAKA, J. Larval rearing. In: PHILLIPS; B. F.; KITTAKA, J. (Ed.). Spiny lobster: fisheries and culture. Cambridge: Fishing News Books, 2000, p. 508-532.
LEWIS, J. B. The phyllosoma larvae of the spiny lobster Panulirus argus. Bulletin of Marine Science Gulf Caribean, Miami, v. 1, n. 2, p. $89-103,1951$.

LIPCIUS, R. N.; COBB, J. S. Ecology and fishery biology of spiny lobsters. In: PHILLIPS, B. F.; COBB, J. S.; KITTAKA, J. (Ed.). Spiny lobster management. Cambridge: Blackwell Scientific Publication, 1994. p. $1-30$.

LYONS, W. G. The postlarval stage of scyllaridean lobsters. Fisheries, USA, v. 5, n. 4, p. 47-49, 1980.

LYONS, W.G.; BARBER, D. G.; FOSTER, S. M.; KENNEDY JUNIOR, F. S.; MILANO, G. R. The spiny lobster, Panulirus argus, in the middle and upper Florida Keys: population structure, seasonal dynamics, and reproduction. Florida Marine Research Publication. Florida, v. 10, n. 38, p. 38, 1981.

MARX, J. M.; HERRNKIND, W. F. Factors regulating microhabitat use by young juvenile spiny lobsters, Panulirus argus: food and shelter. Journal of Crustacean Biology, Woods Holes, v. 5, n. 3, p. 650-657, 1985.

MIKAMI, S.; KUBALLA, A. Overview of lobster aquaculture research. In: THE SECOND HATCHERY FEEDS AND TECHNOLOGY WORKSHOP, 10., 2004, Sydney. Proceedings... Sydney: NCS, 2004. p. 127-130.

MOE JUNIOR, M. A. Lobsters. Florida: Green Turtle Publications. 1991.

MOTA-AlVES, M. I.; BEZERRA R. C. F. Sobre o numero de ovos da lagosta Panulirus argus (Latr.). Arquivo da Estação de Biologia Marinha, Fortaleza, v. 8, n. 1, p. 33-35, 1968.

OLSEN, D. A.; HERRNKIND, W. F.; COOPER, R. A. Population dynamics, ecology, and behavior of spiny lobster Panulirus argus of St. John, U.S. Science Bulletin, Los Angeles, v. 20, n. 1, p. 11-16, 1975.

PHILLIPS, B. F.; SASTRY, A. N. Larval ecology. In: COBB, J. S.; PHILLIPS, B. F. (Ed.). The biology and management of lobsters. New York: Academic Press, 1980 , v. 2, p. 11-57.

WILLIAMS, A. B. Lobster of the world-an illustrated guide. New York: Osprey Books, 1988.

WITHAM, R.; INGLE, R. M.; JOYCE, E.A. Physiological and ecological studies of Panulirus argus from the St. Lucie Estuary, State of Florida. Board of Conservation Technical Series, Florida, v. 1, n. 53, 31 p., 1968.

WITHAM, R.; INGLE, R. M.; SIMS JUNIOR, H. W. Notes on postlarvae of Panulirus argus. Quaterly Journal Florida Academic Science, Florida, v. 27, n. 4, p. 289297, 1964. 